\title{
Ureter: How to Avoid Injuries in Various Hysterectomy Techniques
}

\author{
Manoel Afonso Guimarães Gonçalves, Fernando Anschau, \\ Daniela Martins Gonçalves and Chrystiane da Silva Marc \\ Pontifical Catholic University of Rio Grande do Sul \\ Brazil
}

\section{Introduction}

Hysterectomy is one of the most common surgical procedures in the practice of gynecology. The various surgical techniques for hysterectomy, including those by the abdominal approach as well as those by the vaginal route, deserve special attention with regard to possible transoperative urological injuries. These complications raise questions about the anatomic knowledge for all gynecologists. The ureters are vulnerable to injuries during gynecological surgeries and even obstetric ones due to the anatomic proximity to the organs of the female reproductive system. ${ }^{1}$ The general incidence of ureteral injuries is estimated to be $0.03 \%$ to $2.0 \%$ for abdominal hysterectomy, $0.02 \%$ to $0.5 \%$ for vaginal hysterectomy, and $0.2 \%$ to $6.0 \%$ for laparoscopy-assisted vaginal hysterectomy. 2, 3, 4, 5, 6 There are four critical points of potential ureteral injury during a hysterectomy. The first critical point is situated at the entrance of the ureter in the pelvic bone, when the ovarian vessels cross over it. The second critical point is identified next to the uterosacral ligament, where the ureter is situated lateral to this ligament. The third critical point is at the level of the uterine artery, where the ureter crosses below the uterine artery through the cardinal ligament at the level of the ischial spine. The fourth critical points occurs in the bladder, where the ureter turns medially, crossing the anterior portion of the vaginal dome and entering the bladder wall. ${ }^{7}$ Certainly, the ability to recognize the anatomy, as well the ability of the surgeon in recognizing the points of greater risk of ureter injury, will help in lowering these percentages.

\section{Anatomy}

The ureter is a tube that is part of the urinary tract and that connects the renal pelvis to the bladder. Its function is to transport the urine from the kidney to the bladder, which involves peristaltic or wave-like movements by contraction of its smooth muscle layer. The ureters have three layers, like other tubular organs: (i) the outermost layer consists of connective tissue, partially covered by the serosa in the regions where the ureter is in contact with the peritoneum; (ii) in the intermediate portion, there is a middle layer consisting of smooth muscle tissue of three types, circular, longitudinal and oblique; (iii) the inner layer is composed of mucosa - with transition epithelium - and submucosa - with connective tissue. 
The ureters each have a length of 25 to $30 \mathrm{~cm}$ and a diameter of $3 \mathrm{~mm}$. They originate from the confluence of the various renal calyces, coming together in the renal pelvis. The ureters exit the kidney at the level of the superior abdomen, going down to the pelvis bone behind the organs of the gastrointestinal tract, in the retroperitoneum, medial to the greater psoas muscle. On penetrating the pelvic cavity, crossing over the bifurcation of the common iliac vessels, we also observe the crossing of the ovarian vessels (first critical point of injury). The ureters form the posterior border of the ovarian fossa; they continue caudal to the lateral edge of the uterosacral ligaments (second critical point of injury) up to the cardinal ligament. The uterine artery accompanies the ureter along the lateral part of the cervix and the upper part of the vagina. At the base of the cardinal ligament, the ureter passes below the uterine artery (third critical point of injury), at the level of the ischial spine. At this point it goes initially forward and then medially, under the wide extensive ligament, between the uterine and vaginal arteries, toward the bottom of the lateral sac of the vagina - lying approximately $2 \mathrm{~cm}$ lateral to the cervix. Here, the ureter ascends anterior to the vagina for a short distance finally reaching the base of the bladder, where it opens at a lateral angle of the vesical trigone, obliquely perforating the wall of the bladder (fourth critical point of injury).

In relation to the blood supply of the ureter, it is well established that it is variable and that it is provided from various sources. The abdominal part of the ureter is irrigated regularly by a branch from the abdominal aorta or by a branch of the renal or ovarian artery. At the level of the arched line (the transition point from the abdominal portion to the pelvic portion), the middle portion in general is irrigated by branches of the common or internal iliac arteries. The pelvic portion is irrigated by the superior and inferior vesical arteries, as well as branches from the uterine, mid-rectal and internal pudendal arteries. At its upper and middle portions, blood supply to the ureter comes from the medial side. In contrast, the pelvic ureter receives its vascular supply mainly from the lateral part. Therefore, medial dissection in this distal pelvic portion produces the least vascular damage. Periureteral tissues are also irrigated by the subperitoneal arteries, which allows us to conclude that dissection of the ureters should be minimal in separating them from the peritoneum.

Despite good anatomic knowledge and an experienced surgeon, ureteral injuries can occur due to anatomic distortions. The risk of ureteral injury increases in cases of endometriosis, pelvic adherences or pelvic tumors, which distort the normal course of the ureter. 8 Abnormalities of the urinary tract, which occur in 17 to $20 \%$ of the population, could be documented by preoperative excretory urography; meanwhile, the majority of ureteral injuries occur when there is no indication for excretory urography. 9 The use of this diagnostic technology, like other examinations, for example, cystoscopy, are not indicated in routine preoperative assessment in patients who are going to have a hysterectomy, due to morbidities that, although small, are present in these procedures. The preoperative introduction of ureteral catheters, another method for the identification of ureteral abnormalities and even identification of normal ureteral anatomy, is undesirable because of the cost and associated morbidity. In patients with large pelvic masses that distort anatomy, small uterine segment, cervical myomas or cervical cancer, preoperative imaging studies such as endovenous pyelogram, ultrasound, retrograde pyelography and other studies can be particularly useful. 8

The direct visualization of the ureter should constitute an initial necessary in all pelvic dissections, particularly hysterectomies. The surgeon should feel at ease with the ureteral 
trajectory and well familiarized with the locations of frequent injuries during an abdominal surgery. It is important to recall that routine dissection and repair of the ureters, a procedure to prevent injuries cited by some authors, increases the risks of injury of the ureter and should not be routinely done. ${ }^{10}$

\section{Injuries and their repair}

The adage "just happens to those who make" holds true when we discuss ureteral injuries. Even experienced surgeons, with a substantial volume of pelvic surgeries, at some moment will end up injuring the ureter. Despite being less common than injuries of the bladder and rectum, ureteral injury is one of the most serious complications in gynecological surgery, with high morbidity. The major concern in this case is not always the injury itself, but rather not knowing of its occurrence. The inability to recognize and repair this injury constitutes a great risk for the patient. ${ }^{11}$ Transoperative identification of a ureteral injury occurs in only $11 \%$ to $12 \%$ of cases. ${ }^{12,} 13$

Unexpected pain in the flank region in the postoperative period, fever or vaginal discharge can suggest ureteral injury. Sometimes, the ureteral injuries can go unnoticed because the signs and symptoms are not specific. The $1.7 \%$ incidence of ureteral injuries in hysterectomies concerns some authors when referring to the question of their early identification. Persistent peristalsis was identified in 5 of 6 injured ureters, demonstrating that this sign is a poor marker for determining the integrity of the ureter. ${ }^{12}$

The ureter can be injured in numerous ways: fulgurated, ligated, pinched, jostled and sectioned partially or completely. Besides these injuries, trauma to the sheath of the ureter and to its longitudinal blood supply can occur (devascularization), despite a technique of meticulous dissection.

Injuries due to ligature, pinching or jostling of the ureter occur more often in the locations where the ovarian and uterine vessels are ligated or clamped. ${ }^{14}$ If they are soon noticed, the simple removal of a wrongly placed suture can be sufficient for repair. However, injuries caused by clamping produce significant damage of the crush type. After removal of the hemostat, the tissues should be examined with respect to their viability, and if there is still vitality, it is likely that the placement of ureteral catheters will be sufficient. If any segment appears to be nonviable, it should be excised.

The ureteral sections can be partial or complete. The partially sectioned ureters should also be evaluated with respect to their vitality. Vascularized tissue can be reapproximated by an absorbable suture on a ureteral catheter. Repair of complete sections can vary with localization and extent of vascular damage. If the injury occurs distant from the bladder, it can be repaired on a ureteral catheter. The proximal and distal ends should be mobilized and resutured without any tension.

The location of the injury constitutes an important element in the choice of the repair technique. Approximately 80 to $90 \%$ of the injuries occur in the terminal ureter. In this situation, a form of ureteral reimplantation can be indicated. For the injuries less than $5 \mathrm{~cm}$ of the ureterovesical junction, a simple reimplantation can be complicated by urinary reflux, and therefore, some authors, recommend the creation of a submucosal tunnel of the vesical wall. In this technique, the dome of the bladder is opened to choose the most inclined part of 
the vesical base, where a tunnel is made, creating a submucosal passage of approximately $1.5 \mathrm{~cm}$. The ureter should be drawn through the tunnel with delicate traction. A mucosamucosa anastomosis over a catheter is made utilizing a fine absorbable suture. A second set of sutures supports the anastomosis, uniting the ureteral adventitia and the vesical muscle. The closing of the bladder should be done with double plane suturing with a fine absorbable suture.

For higher injuries - above $5 \mathrm{~cm}$ from the ureterovesical junction- and in those in which it is not possible to unblock the ureter or where a complete sectioning has occurred or the ureter crushed, some procedure will be necessary to mobilize the ureter and/or bladder so that the reimplantation site is not under tension. This method can consist of the dissection of the healthy portion of the ureter and its sectioning above the location of the injury. ${ }^{15}$ The injured end of the ureter should be ligated to avoid extravasation of urine from the bladder, proceeding then to the choice of a site for reimplantation of the ureter in the posterior portion of the vesical fundus. The bladder is opened and its wall is transfixed from inside to outside with curved forceps, pulling the ureter through this orifice. The ureteral orifice is sutured to the muscle and mucosa layers of the bladder with a fine 4-0 absorbable suture. The ureter can also be tunnelized in the vesical submucosa before performing the anastomosis. A double J ureteral catheter is introduced, where it is removed after about 6 weeks. The vesical wall is sutured in planes with a 3-0 absorbable suture, and the bladder examined for 7 to 10 days by the supra-pubic and urethral route with two No. 20 Foley probes. One of these probes can be removed as soon as the patient no longer shows macroscopic hematuria, where excretory urography is performed after the removal of the double J catheter for anatomic evaluation of the urinary tract. The success of ureteral reimplantation surgery (ureteroneocystostomy) described here depends on the realization of an anastomosis between the ureter and bladder absolutely free of tension. To achieve this, it is often necessary to fix the bladder on the major psoas muscle of the compromised side. ${ }^{16}$

Various conditions contribute in determining the incidence of ureteral injuries in gynecological practice. The relations of contiguity between the pelvic ureter and the genital tract, on the one hand, and the possible direct or indirect participation of the ureter in genital pathology, on the other hand, represent the presumptions about the ureteral pathology of gynecological interest. The intimate relation that the pelvic ureter has with the genital tract explains how many inflammatory or tumor processes can compromise it directly or cause its topographic modification.

In the classification of ureteral injuries, a very useful difference for clinical purposes is separately considering the ureteral injuries diagnosed at the moment of the surgical act and others in which clinical manifestations emerged after some time. In injuries found during the surgical intervention, its repair requires only technical knowledge of its resolution, generally with low morbidity. However, for injuries diagnosed later, the problems will be of various natures, showing variable symptomatology and complex diagnostic and therapeutic possibilities.

When there is ureteral injury, the therapy is in general subordinated to the type and site of the ureteral injury, to the type of intervention during which the injury was caused, and to the nature and extent of the disease which determined the surgical intervention.

We describe below the ureteral injuries during abdominal interventions for benign problems. 


\section{Abdominal hysterectomy}

It is in this intervention that a large number of ureteral injuries are found. For a clear description of the various possibilities of the ureteral injuries in relation to various techniques, we will consider separately the various times of this intervention in which the injury can be produced. Certainly, we should make an essential observation in the approach of the abdominal hysterectomy and ureteral injuries: some authors believe that there is increased risk of injury for the laparoscopic route that, although small - with $1.1 \%$ prevalence, representing 7.2 times the risk demonstrated in laparotomy procedures. ${ }^{17}$ However, based on meta-analysis that considered all the complications of major severity, including ureteral injuries, there would be no difference in the incidence of these major complications between laparotomic and laparoscopic techniques. ${ }^{18}$

\subsection{At the level of the ovarian pedicle}

The injury that can occur during the clamping and sectioning of the ovarian vessels is a relatively rare incident under normal conditions. However, some congenital or acquired situations can favor the injury, such as congenitally short ovarian pedicle, presence of an adnexial inflammatory process or the growth of a tumor with intra-ligamentary development. Besides, it should be pointed out that an injury can occur during the ligature of the ovarian vessels with an insufficient clipping of the vessels and their consequent retraction, with the approximation of the ureter. The attempt at successive hemostasis in these situations can lead to a ureteral injury. A better prophylaxis of ureteral injuries at this level would be a careful and precise preparation of the ovarian pedicle and freeing it from pathological adherences before the ligature of the ovarian vessels. 19

\subsection{At the level of the uterosacral ligament}

In the sectioning of the uterosacral ligament, the possibility of a ureteral injury often becomes real due to the retractions caused by pelvic peritonitis or especially in not very rare cases of endometriosis next to this ligament. As we know, the ureter passes below and lateral to the uterosacral ligament, and therefore, when sectioning this ligament, the ureter can be injured.

This accident can be avoided with the sectioning of the peritoneum at the bottom of Douglas' sac and with traction of the uterus upward toward the pubic symphysis. With this maneuver, the ureter is separated and we can observe the rectal columns better, which can also be retracted. These ligaments can be sectioned by electrosurgery or clamped and sectioned horizontally and separate from the cardinal or Mackenrodt ligament, through which the ureter passes.

\subsection{At the level of mackenrodt's ligament}

At this point, we have the crossing of the ureter with the uterine artery. The most frequent injuries in total hysterectomy occur at the moment of the sectioning of Mackenrodt's ligament. Various determinants can be responsible for this, but those that deserve special attention are the inflammatory abnormalities that favor the retraction of the parametrium and allow the most frequent occurrence of this accident. Prophylaxis of this injury is done respecting the surgical technique in which the bladder is first mobilized, especially in the 
middle zone, individualizing the vesical columns, which should be distended laterally, allowing the ureters to be separated. ${ }^{15}$ The ureters, in this way, remain laterally, which allows the secure ligatura of the uterine vessels followed by Mackenrodt's ligament. Inflammatory reactions or neoplasms that cause a blockage in this region can result in difficulties in executing this technique.

In these cases, the ureter should be first individualized and dissected up to its entrance into the parametrium. In many situations, this is the moment for making a tunnel between the ureter and the parametrium, identifying clearly the artery and the uterine vein, which are above the ureter. On sectioning the roof of the tunel, after its clamping, hemostasis of the uterine vascular bundle is also performed. In this way, this surgical time, even in adverse situations, can be done with little chance of accidents.

\subsection{At level of the bladder}

Ureteral injuries at level of the bladder are of concern when there is large dissection of the tissues in this related anatomic region, for example, in extrafascial total hysterectomy and radical hysterectomy. Even so, after the surgical time of the sectioning of Mackenrodt's ligament, taking the usual technical precautions, these injuries are infrequent. Surgical precautions include dissection with caudal separation of the bladder after ligature of the uterine vessels, associated with contralateral traction of the uterus, and moving the ureter away from the surgical field, increasing the distance between the ureter and the cervix. This maneuver positions the ureter more inferior and lateral to Mackenrodt's ligament (already sectioned). In this way, the sectioning of the vaginal wall for the extraction of the uterus will be free of risks of ureteral injury at the level of its entrance in the bladder.

\subsection{In the presence of myoma}

Injury of the ureter during a surgical intervention with myomatous uterus remains subordinate to the location and volume of the myoma and to the degree of topographic dislocation of the ureter that the myoma may have caused. Myomas located in the cervical or intra-ligamentary regions can make the surgery more difficult, providing a greater chance of ureteral injuries.

Generally, the ureter remains compromised, in these cases below the myoma, but can sometimes be over the myoma. This situation occurs when the myoma develops in the lower part of the isthmus. A better prophylaxis of this accident is to individualize the ureter by dissection of the retroperitoneum.

\subsection{Adnexectomy}

Adnexectomy when performed alone or together with hysterectomy can favor surgical injuries of the ureter. We can have infectious clinical situations, pictures of endometriosis, ectopic pregnancies with involvement of all tube, malignant or benign neoplastic problems such as intra-ligamentary cysts, which favor an injury of the ureter.

Operative maneuvers should adapt to each circumstance where there is always the possibility of the injury of the ureter, which with the growth of a cystic formation can undergo modifications in its topography. 


\section{Vaginal hysterectomy}

Even if ureteral injuries can happen in the course of this intervention, we should point that this accident can be avoided simply by carrying out the surgical technique in a correct manner. The rate of ureteral injuries is low, around $0.88 \%$, and remain less than that of vesical injury, around $1.76 \%$, in vaginal hysterectomy without prolapse. ${ }^{20}$

The possibility of injury of the ureter can occur soon after sectioning Mackenrodt's ligament, when we proceed with the ligature of the uterine artery, when there can be the need for of successive attempts at hemostasis. To avoid the injury, it is sufficient to mobilize the bladder in the direction of the vesico-uterine peritoneal fold and even to pull the cervix down and in the direction opposite to the side of the parametrium to be sectioned.

\subsection{In adnexectomy}

Another moment in which an injury of the ureter can occur in vaginal hysterectomy is when there is the need for an adnexectomy. On the occasion of ligature of the ovarian pedicle, by slipping the loop of the suture over the vessels, these can withdraw, causing bleeding and in the attempt of successive hemostasis, with new hemostats, the ureter can be included, leading to its injury. The care that should taken when this happens is to isolate the bleeding vessel, and to clamp it individually, never blindly or en masse. If during the surgery, it is decided to close the peritoneum, there is the risk of the angulation of the ureter at the level of the ovarian pedicle.

\section{Radical hysterectomy (Wertheim-Meigs)}

Even though it may appear paradoxical, direct ureteral injuries in these interventions are less frequent than in the execution of total hysterectomy due to benign injuries. The description of ureteral injuries in radical hysterectomy is on the order of $0.77 \%$ to $1.32 \%$. ${ }^{21}, 22$ In performing a radical hysterectomy, injuries can occur by contusion of the ureter which can translate into later fistulas. Eventual accidents can occur in unfavorable situations such as in deeper planes, with an imperfect exposure of the surgical field or with difficult hemostatic control, leading to failure in a routine surgical technique.

\section{References}

[1] Jung SK, Huh CY. Ureteral injuries during classic intrafascial supracervical hysterectomy: an 11-years experience in 1163 patients. J Minim Invasive Gynecol. 2008;15(4):440-445.

[2] Goodno JA Jr, Powers TW, Harris VD. Ureteral injury in gynecologic surgery: a ten year review in a community hospital. Am J Obstet Gynecol. 1995; 172:1817-1820.

[3] Harkki-Siren P, Sjoberg J, Tiitinen A. Urinary tract injuries after hysterectomy. Obstet Gynecol. 1998; 92:113-118.

[4] Stanhope CR, Wilson TO, Utz WJ, Smith LH, O'Brien PC. Suture entrapment and secondary ureteral obstruction. Am J Obstet Gynecol. 1991; 164:1513-1517.

[5] Wu HH, Yang PY, Yeh GP, Chou PH, Hsu JC, Lin KC. The detection of ureteral injuries after hysterectomy. J Minim Invasive Gynecol. 2006; 13:403-408. 
[6] Gilmour DT, of the S, Flowerdew G. Rates of urinary tract injury from gynecologic surgery and the role of intraoperative cystoscopy. Obstet Gynecol. 2006; 107(6):1366-1372.

[7] Berek J. Berek and Novak's Gynecology. 14th ed. Philadelphia, PA: Lippincott Williams and Wilkins; 2006. p.123-124.

[8] Ferro A, Byck D, Gallup D. Am J Obstet Gynecol. 2003;189(2):354-357.

[9] Piscitelli JT, Simel DL, Addison WA : Who should have intravenous pyelograms before hysterectomy for benign disease. Obstet Gynecol. 1987;69:541-544

[10] Buller JL,Thompson JR, Cundiff GW, et al. Uterosacral ligament: description of anatomic relatioships to optimize surgical safety. Obstet Gynecol. 2001;97:873-879.

[11] Higgins CC: Ureteral injuries during surgery: a review of 87 cases. JAMA. 1967;199:8286.

[12] Vakili B, Chesson RR, Kyle BL, et al. The incidence of urinary tract injury during hysterectomy: a prospective analysis based on universal cystoscopy. Am J Obstet Gynecol. 2005; 192:1599-1604.

[13] Gilmour DT, Dwyer PL, Carey MP. Lower urinary tract injury during gynecologic surgery and its detection by intraoperative cystoscopy. Obstet Gynecol. 1999; 94:883-889.

[14] Daly, JW, Higgins KA: Injury to the ureter during gynecologic surgical procedures. Surg Gynecol Obstet. 1988;167:19-22.

[15] Utrie JW. Bladder and ureteral injury: prevention and management. Clin Obstet Gynecol. 1998; 41:755-763.

[16] Ehrlich RM, Melman A, Skinner DG. The use of the vesico-psoas hitch in urologic surgery. J Urol. 1978; 119:322-326.

[17] Mäkinen J, Johansson J, Tomás C, et al. Morbidity of 10110 hysterectomies by type approach. Human Reprod. 2001; 16(7):1473-1478.

[18] Walsh CA, Walsh SR, Tang TY, Slack M. Total abdominal hysterectomy versus total laparoscopic hysterectomy for benign disease: a meta-analysis. Eur J Obstet Gynecol Reprod Biol. 2009; 144:3-7.

[19] Messaoudi F, Ben Jemaa S, Yazidi M, et al. Lower urinary trauma complication gyneacologic and obstetrical surgery. Tunis Med. 2008; 86(8):740-744.

[20] Ibeanu AO, Chesson RR, Echols KT, et al. Urinary tract injury during hysterectomy based on universal cystoscopy. Obstet Gynecol. 2009; 113:6-10.

[21] Frankman EA, Wang L, Bunker CH, Lowder JL. Lower urinary tract injury in women in the United States, 1976-2006. Am J Obstet Gynecol. 2010; 202(5):495.e1-5.

[22] Likic IS, Kadija S, Ladjevic NG, et al. Analysis of urologic complications after radical hysterectomy. Am J Obstet Gynecol. 2008; 199(6):644.e1-3. 


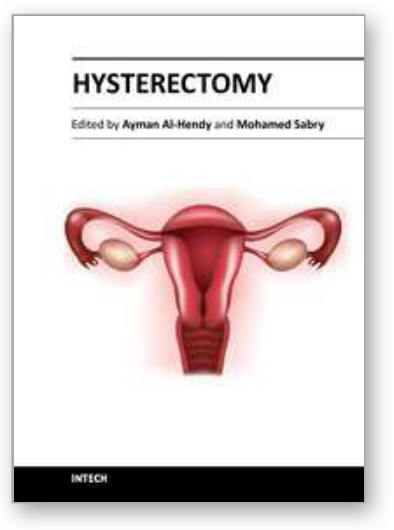

\author{
Hysterectomy \\ Edited by Dr. Ayman Al-Hendy
}

ISBN 978-953-51-0434-6

Hard cover, 426 pages

Publisher InTech

Published online 20, April, 2012

Published in print edition April, 2012

This book is intended for the general and family practitioners, as well as for gynecologists, specialists in gynecological surgery, general surgeons, urologists and all other surgical specialists that perform procedures in or around the female pelvis, in addition to intensives and all other specialities and health care professionals who care for women before, during or after hysterectomy. The aim of this book is to review the recent achievements of the research community regarding the field of gynecologic surgery and hysterectomy as well as highlight future directions and where this field is heading. While no single volume can adequately cover the diversity of issues and facets in relation to such a common and important procedure such as hysterectomy, this book will attempt to address the pivotal topics especially in regards to safety, risk management as well as pre- and post-operative care.

\title{
How to reference
}

In order to correctly reference this scholarly work, feel free to copy and paste the following:

Manoel Afonso Guimarães Gonçalves, Fernando Anschau, Daniela Martins Gonçalves and Chrystiane da Silva Marc (2012). Ureter: How to Avoid Injuries in Various Hysterectomy Techniques, Hysterectomy, Dr. Ayman Al-Hendy (Ed.), ISBN: 978-953-51-0434-6, InTech, Available from: http://www.intechopen.com/books/hysterectomy/ureter-how-to-avoid-lesions-in-various-hysterectomytechniques-

\section{INTECH}

open science | open minds

\section{InTech Europe}

University Campus STeP Ri

Slavka Krautzeka 83/A

51000 Rijeka, Croatia

Phone: +385 (51) 770447

Fax: +385 (51) 686166

www.intechopen.com

\section{InTech China}

Unit 405, Office Block, Hotel Equatorial Shanghai No.65, Yan An Road (West), Shanghai, 200040, China 中国上海市延安西路65号上海国际贵都大饭店办公楼405单元 Phone: +86-21-62489820

Fax: $+86-21-62489821$ 
(C) 2012 The Author(s). Licensee IntechOpen. This is an open access article distributed under the terms of the Creative Commons Attribution 3.0 License, which permits unrestricted use, distribution, and reproduction in any medium, provided the original work is properly cited. 